\title{
Changing priorities in maternal and perinatal health in Gert Sibande District, South Africa
}

\author{
M Bac, ${ }^{1}$ Arts (EUR), MFamMed, MD; R C Pattinson, ${ }^{2}$ BSc, MB ChB, MMed (O\&G), FGOG (SA), MD, FRCOG; A-M Bergh, ${ }^{2}$ PhD \\ ${ }^{1}$ Department of Family Medicine, School of Medicine, Faculty of Health Sciences, University of Pretoria, South Africa \\ ${ }^{2}$ South African Medical Research Council Maternal and Infant Health Care Strategies Unit, Department of Obstetrics and Gynaecology, \\ School of Medicine, Faculty of Health Sciences, University of Pretoria, South Africa
}

Corresponding author: M Bac (martin.bac@up.ac.za)

Gert Sibande District is a predominantly rural district in Mpumalanga Province, South Africa (SA), with a population of just over 1.1 million. It has a high prevalence of HIV infection and pregnancy-related hypertensive disease. In 2010 the district was one of the worst-performing health districts in SA, with a maternal mortality ratio of 328.0 per 100000 births. Various programmes were introduced between 2010 and 2017 to address major causes of maternal and perinatal morbidity and mortality in the district. The focus has been on HIV-related morbidity, the direct obstetric causes of maternal and perinatal morbidity and mortality, and health systems strengthening. During the period 2010 - 2017, there was a steady decline in institutional maternal mortality with a drop of $71 \%$ in maternal deaths over a period of 6 years, from 328.0 per 100000 births to 95.0. However, the ratio levelled off in 2016 and 2017, mainly as a result of a changing disease profile. The stillbirth rate showed a decline of $24.4 \%$ over a period of 8 years. With perseverance, rapid response and evidence-based strategies it was possible to more than halve the institutional maternal mortality ratio within 6 years. However, with the changing disease profile, conditions such as hypertensive disease in pregnancy should be prioritised and new strategies developed to further reduce maternal and perinatal mortality and morbidity.

S Afr Med J 2019;109(11):838-840. https://doi.org/10.7196/SAMJ.2019.v109i11.14098

Health systems in low- and middle-income countries worldwide are actively engaged in finding solutions for improving maternal and perinatal health and reducing mortality. The Millennium Development Goals (MDGs) appraised South Africa (SA)'s position and identified the shortfalls in achieving these goals. The targets of the Sustainable Development Goals (SDGs) are currently being embraced. ${ }^{[1]}$ Intervention programmes that are making a difference are multifaceted and are mostly related to resources, skills and health systems. ${ }^{[2]}$ Programmes need to target the main killers such as HIV-related deaths from tuberculosis, pneumonia, meningitis and other opportunistic infections, obstetric haemorrhage, hypertensive diseases of pregnancy (HDP) and pregnancy-related sepsis. ${ }^{[3,4]}$

In this article, we describe successive interventions to combat the high maternal and perinatal mortality and morbidity in one health district in SA during the period 2010 - 2017. We argue for the importance of continuous surveillance and response and the use of available data to continuously monitor changes and trends to guide decisions on prioritisation of the most appropriate, cost-effective interventions.

\section{Characteristics of Gert Sibande District}

The focus of this case study is Gert Sibande District (GSD) in Mpumalanga Province, SA, a predominantly rural district with an estimated population of just over 1.1 million in 2016. ${ }^{[5]}$ The main economic activities are manufacturing and agriculture. ${ }^{[6]}$ The human development index of the district was 0.60 in $2013,{ }^{[6]}$ and the unemployment rate was $35.4 \%$ in $2011 .{ }^{[6]}$ The district had some of SA's poorest health outcomes. In 2011, the $46.1 \%$ HIV prevalence among pregnant women aged 15 - 49 years who were attending antenatal clinics was the highest in the country. ${ }^{[6,7]}$ The district's maternal mortality ratio stood at 328.0 per 100000 live births in $2010,{ }^{[3,4]}$ and the perinatal mortality rate was 36.5 per 1000 births (unpublished data from the Perinatal Problem Identification Programme). Both rates were among the highest in the country. In 2011 - 2013, the major causes of maternal mortality were nonpregnancy-related infections (37.0\%), obstetric haemorrhage (18.5\%) and hypertension (13.0\%). ${ }^{[3]}$ GSD was one of the 11 pilot districts for the first phase of the implementation of universal access to healthcare through National Health Insurance during the period 2012 - 2017. ${ }^{[8]}$ During the past decade, maternal and child health-orientated quality improvement projects by medical and clinical associate students of the University of Pretoria were included in some of the subdistricts.

\section{Complex healthcare interventions}

This case study illustrates the complexity of healthcare interventions aimed at improving maternal and perinatal health and the difficulty in determining the impact of individual interventions. Many of the interventions between 2010 and 2017 described below were directed from the National Department of Health $(\mathrm{NDoH})$, but others specifically targeted our case district.

- The major intervention, with the biggest impact on maternal and child health countrywide, was implementation of the 2010 Guidelines for the Prevention of Mother-to-Child Transmission (PMTCT) of HIV. ${ }^{[9]}$ Currently, all HIV-infected pregnant and breastfeeding women are eligible for lifelong highly active antiretroviral therapy (HAART). HIV-exposed babies of breastfeeding women also receive treatment while being breastfed and are tested regularly. ${ }^{[10]}$ Implementing these guidelines required task-shifting from doctors and the roll-out of a large-scale initiative to train primary healthcare nurses in Nurse Initiation and Maintenance of Antiretroviral Therapy ${ }^{[11]}$ In a limited study that 
included community health centres in GSD, the rate of antiretroviral prescription immediately following diagnosis or entry into antenatal care ranged from $54 \%$ to $100 \%{ }^{[12]}$

- In reaction to the non-attainment of MDGs 4 and 5, the Minister of Health instituted multiprofessional district clinical specialist teams (DCSTs) in all health districts in 2012. These teams are specifically tasked with initiating and overseeing quality improvement projects in maternal, newborn and child health using audit and observation tools. ${ }^{[13]}$ Although GSD does not have a complete DCST, specific outreach activities have been conducted, such as training in safe caesarean sections in district hospitals in 2015 - 2016.

- At the same time, the Essential Steps in the Management of Obstetric Emergencies programme (ESMOE) was introduced in 2012 in GSD, which had been identified as one of the 12 'most-in-need' districts. This is an off-site, structured knowledge-andskills training programme that covered at least $80 \%$ of midwifery and medical staff. One of the key elements is the regular performance of emergency drills after initial training. The workshops included an HIV module, which reinforced the latest PMTCT messages. This programme resulted in a $29.3 \%$ drop in overall mortality and a $17.5 \%$ drop in direct causes of maternal deaths in the 12 districts. ${ }^{[14]}$

- SA's MomConnect mobile messaging programme was launched in 2014 and aims to promote safe motherhood and improve pregnancy outcomes for SA women. It includes a helpdesk feature that allows women registered on the system to ask questions related to maternal and child health and to provide feedback on health services received at public health facilities. MomConnect is the only mobile health programme in the world to have reached $>60 \%$ coverage of all pregnant women nationally, with 1.7 million subscribers registered since its launch. ${ }^{[15]}$

- In 2014, the NDoH introduced the ' 3 feet model' in three of the worst-performing districts in the country, which included GSD. The model operates without additional funding and is based on two complementary entry points: monitoring and response units with compulsory 24-hour death reporting and response, and quality improvement with outreach and in-reach activities. ${ }^{[16]}$

- Basic Antenatal Care Plus (BANC+) is an improved basic antenatal care package, with an additional four health visits, that was introduced in all health districts in SA in April 2017 to proactively detect and treat asymptomatic HDP and other complications in the last trimester of pregnancy. The increased antenatal care contacts in the third trimester have raised the number of women diagnosed with hypertension in pregnancy by $46 \%$ at the four SA sites where the intervention is being monitored. ${ }^{[17]}$ Time will tell whether this increased detection leads to a reduction in mortality. This change was based on recommendations by a working group to the National Health Council that described HDP as the second most common cause of stillbirths in the third trimester and the unchanged institutional maternal mortality ratio of HDP over one decade (Gebhardt G, Pattinson R, Hofmeyr J, et al., 'Basic Antenatal Care (BANC) package in South Africa - motivation to increase the routine number of antenatal visits', unpublished report presented to the South African National Health Council on 24 November 2016). The proposal was accepted by the Minister of Health. DCST members were trained as master trainers and were expected to do the further training required in the district. Pregnant women receive information relevant to their pregnancy and the increased number of visits via MomConnect.

\section{Changes in mortality}

Fig. 1 illustrates the trend in institutional maternal deaths and stillbirths in GSD between 2010 and 2017. Initially there was a decrease in the institutional maternal mortality ratio (iMMR). This has levelled off since 2014 because of the change in disease profile, with non-pregnancy-related infections (i.e. HIV-related co-infections) becoming less important after the successful roll-out of the PMTCT programme. For example, the iMMR for non-pregnancy-related infections showed a significant drop from 75.37 per 100000 live births in the triennium 2011 - 2013 to 26.78 in the triennium $2014-2016$. For the same two triennia there was a non-significant trend of reduction in deaths due to obstetric haemorrhage (37.89 and 28.69 per 100000 live births, respectively). There was no change in mortality due to HDP (26.38 and 26.78 per 100000 live births, respectively). ${ }^{[3,4]}$

Stillbirth rates decreased by $24.4 \%$ in GSD between 2010 and 2017. Table 1 provides an overview of the 2010 - 2017 perinatal, stillbirth and early neonatal mortality. ${ }^{[3,4,18]}$ The early neonatal mortality rate showed a reduction of $11 \%$ for this period, as against a drop of $20 \%$ in the perinatal death rate. The perinatal care index is a measure of the quality of care, calculated as the perinatal mortality rate divided by the low-birthweight rate. ${ }^{[19]}$ GSD showed an improvement of $13.0 \%$ in its perinatal care index - from 2.32 to 2.0 - over the period.

\section{Lessons learint}

During the period 2010 - 2013, the major causes of maternal morbidity and mortality were non-pregnancy-related infections.

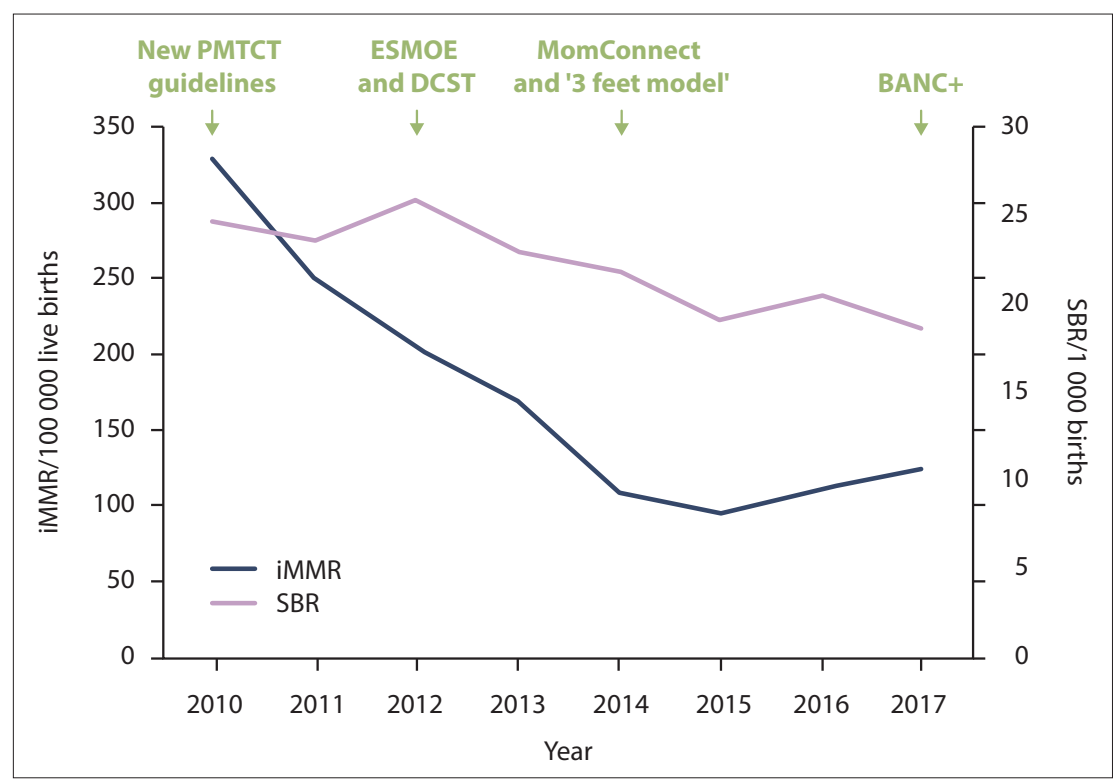

Fig. 1. Maternal mortality and stillbirth trends in Gert Sibande District, 2010 - 2017. (PMTCT = prevention of mother-to-child transmission; ESMOE = Essential Steps in the Management of Obstetric Emergencies programme; DCST = district clinical specialist team; BANC+ = Basic Antenatal Care Plus; $i M M R=$ institutional maternal mortality ratio; $S B R=$ stillbirth rate.) 
Table 1. Perinatal, stillbirth and early neonatal mortality rates in Gert Sibande District, 2010 - 2017

\begin{tabular}{llll}
\hline & PNMR & SBR & ENNMR \\
\hline 2010 & 36.5 & 24.6 & 12.2 \\
2011 & 35.9 & 23.6 & 12.6 \\
2012 & 36.8 & 25.9 & 11.1 \\
2013 & 31.3 & 23.0 & 8.5 \\
2014 & 31.6 & 21.8 & 10.0 \\
2015 & 30.2 & 19.1 & 11.4 \\
2016 & 32.3 & 20.5 & 12.0 \\
2017 & 29.3 & 18.6 & 10.9
\end{tabular}

PNMR = perinatal mortality rate per 1000 births; SBR = stillbirth rate per 1000 births; ENNMR = early neonatal mortality rate per 1000 live births.

Within a few years after the scale-up of HAART in the PMTCT programme, a significant improvement in maternal wellbeing and morbidity was noted. With continuous monitoring it became clear that the next major cause to be addressed was obstetric haemorrhage. This was achieved by means of ESMOE training for doctors and midwives, followed by regular emergency drills. The most recent analysis of data reveals that during the past decade there has been no reduction in the number of deaths due to HDP. The next step is the development of new guidelines for the detection and management of hypertension in pregnancy.

SA has an extensive audit system for maternal and perinatal deaths in the form of the Confidential Enquiry into Maternal Deaths in South Africa and the Perinatal Problem Identification Programme, complemented by the District Health Information System. These programmes make provision for the continuous monitoring of data, which in turn enables the identification of priority changes that could improve maternal and perinatal health and the implementation of cost-effective interventions. It is, however, also important to maintain the gains that have resulted from the full implementation of the earlier interventions.

For further progress in achieving the SDGs for maternal and newborn health, the quality of antenatal and intrapartum care needs further improvement. The new national intrapartum guidelines based on the World Health Organization's recommendations for a positive childbirth experience ${ }^{[20]}$ and guidelines for managing specific obstetric conditions such as hypertension in pregnancy should be implemented at all levels of care and by the whole team of health professionals responsible for maternal and newborn health services. This can only be achieved if there is good integration of the different levels of care in the community, primary healthcare clinics and community health centres, high-risk antenatal clinics, district hospitals and referral hospitals for patients with complications.

\section{Declaration. None.}

Acknowledgements. We thank the District Management Team of GSD, Dr Jorge Perez, the obstetrician of the DSCT, and the family physicians and hospital chief executive officers who provided crucial information on the situation on the ground.

Author contributions. $\mathrm{MB}, \mathrm{RCP}$ and $\mathrm{A}-\mathrm{MB}$ conceptualised the focus of the article. RCP did the statistical analysis. MB and A-MB wrote the first draft, with further inputs from RCP.
Funding. There was no special funding for compiling this report. The information was, however, sourced from different public domain reports and projects funded by various agencies and health departments.

Conflicts of interest. None.

1. United Nations Economic Commission for Africa. Sustainable Development Goals for the Southern Africa Subregion: Summary Report. Addis Ababa: UNECA, 2015. https://www.uneca.org/sites/ default/files/PublicationFiles/southern_africa_sdg_summary_report_english.pdf (accessed 26 September 2018)

2. Pattinson R, Kerber K, Buchmann E, et al. Stillbirths: How can health systems deliver for mother and babies? Lancet 2011;377(9777):1610-1623. https://doi.org/10.1016/S0140-6736(10)62306-9

3. National Committee for Confidential Enquiry into Maternal Deaths. Saving Mothers 2011 - 2013 National Committee for Confidential Enquiry into Maternal Deaths. Saving Mothers $2011-2013$ :
Sixth Report on Sixth Report on Confidential Enquiries into Maternal Deaths in South Africa: Short Report.
Pretoria: National Department of Health, 2014. http://www.kznhealth.gov.za/mcwh/Maternal/ Saving-Mothers-2011-2013-short-report.pdf (accessed 28 September 2019).

4. National Committee for Confidential Enquiry into Maternal Deaths. Saving Mothers 2014 - 2016 Seventh Triennial Report on Confidential Enquiries into Maternal Deaths in South Africa: Shor Report. Pretoria: National Department of Health, 2017. https://www.sasog.co.za/Content/Docs Saving_Mothers.pdf (accessed 28 September 2019).

5. Statistics South Africa. Provincial Profile: Mpumalanga. Community Survey 2016. Report 03-01-13. Pretoria: Stats SA, 2018. http://cs2016.statssa.gov.za/wp-content/uploads/2018/07/Mpumalanga.pdf (accessed 2 December 2018).

6. Municipalities of South Africa. Gert Sibande District Municipality (DC30). Overview. https:// municipalities.co.za/overview/132/gert-sibande-district-municipality (accessed 27 September 2019).

7. Mpumalanga Province, Department of Health. Annual report 2012 - 13. http://pmg-assets.s3website-eu-west-1.amazonaws.com/mpumalanga_doh_annual_report_2012-2013.pdf (accessed 26 Sepwebsite-eu-west-1.

8. Genesis Analytics. Evaluation of Phase 1 implementation of interventions in the National Health 8. Genesis Analytics. Evaluation of Phase 1 implementation of interventions in the National Health
Insurance (NHI) pilot districts in South Africa. NDOH10/2017-2018. Final evaluation report Insurance (NHI) pilot districts in South Africa. NDOH10/2017-2018. Final evaluation report
July 2019. https://www.hst.org.za/publications/NonHST\%20Publications/nhi_evaluation_report_ final_14\%2007\%202019.pdf (accessed 27 September 2019).

9. Republic of South Africa. National Consolidated Guidelines for the Prevention of Mother-tochild Transmission of HIV (PMTCT) and the Management of HIV in Children, Adolescents and Adults. Pretoria: National Department of Health, 2015. http://www.sahivsoc.org/Files/ART\%20 Guidelines\%2015052015.pdf (accessed 26 September 2018).

10. Burton R, Giddy J, Stinson K. Prevention of mother-to-child transmission in South Africa: An everchanging landscape. Obstet Med 2015;8(1):5-12. https://doi.org/10.1177/1753495X15570994

11. Cameron D, Gerber A, Mbatha M, Mutyabule J, Swart H. Nurse initiation and maintenance of patients on antiretroviral therapy: Are nurses in primary care clinics initiating ART after attending NIMART training? S Afr Med J 2012;102(2):98-100.

12. Peltzer K, Prado G, Horigian V, et al. Prevention of mother-to-child transmission (PMTCT) implementation in rural community health centres in Mpumalanga province, South Africa. implementation in rural community health centres in Mpumalanga province,
J Psychol Afr 2016;26(5):415-418. https://doi.org/10.1080/14330237.2016.1219537

13. Ministerial Task Team. District Clinical Specialist Teams in South Africa: Ministerial Task Team Report to the Honourable Minister of Health, Dr Aaron Motsoaledi. 2012. http://www.google co.za/url?sa $=t \& r c t=j \& q=\&$ esrc $=s \&$ source $=$ web $\& c d=\&$ ved $=0$ ahUKEwiY 64 fqp N3RAhVLKMAKH YrUDxgQFggjMAE\&url=http\%3A\%2F\%2Fwww.health.gov.za\%2Findex.php\%2F2014-08-15-1255-04\%2Fcategory\%2F100-2012rp\%3Fdownload\%3D186\%3Adistrict-clinical-specialist-teams-insouth-africa-ministerial-task-team-report\&usg=AFQjCNFf4InCkNYzBB55uyOAFB1wdR3A0fw (accessed 30 January 2018).

4. Pattinson RC, Bergh A-M, Ameh C, et al. Reducing maternal deaths by skills-and-drills training in managing obstetric emergencies: A before-and-after observational study. S Afr Med 2019;109(4):241-245. https://doi.org/10.7196/SAMJ.2019.v109i4.13578

15. Peter J, Benjamin P, LeFevre AE, Barron P, Pillay Y. Taking digital health innovation to scale in South Africa: Ten lessons from MomConnect. BMJ Glob Health 2018;3:e000592. https://doi.org/10.1136/ bmigh-2017-000592

16. Schneider H, McKenzie A, Tabana H, Mukinda F, George A. Evaluation of District-based Strengthening Initiatives for Improving the Quality and Outcomes of Maternal, Neonatal and Child Health Care in Four South African Districts. Cape Town: School of Public Health, University of the Western Cape, 2017. https://www.researchgate.net/profile/Helen_Schneider2/publication/322399652 Western Cape, 2017. https://www.researchgate.net/profile/Helen_Schneider2/publication/322399652_ Evaluation_of_health_system_strengthening_initiatives_for_improving_the_quality_and_
outcomes_of_maternal_neonatal_and_child_health_care_in_four_South_African_districts/ outcomes_of_maternal_neonatal_and_child_health_care_in_four_South_African_districts/
links/5a577fb00f7e 9 bbacbdefo8e/Evaluation-of-health-system-strengthening-initiatives-forimproving-the-quality-and-outcomes-of-maternal-neonatal-and-child-health-care-in-four-SouthAfrican-districts.pdf (accessed 15 September 2018)

17. Hlongwane TMAG, Nkosi BSS, Vannevel V, Pattinson R. The effects of implementing Basic Antenata Care (BANC) Plus on workload, detecting hypertension and perinatal mortality. Presented at the 37th Conference on Priorities in Perinatal Care in Southern Africa, Champagne Castle Sports Resort, Drakensberg, South Africa, 13 - 16 March 2018. https://www.perinatalpriorities.co.za/wpcontent/uploads/2014/12/Abstract-book-2018.pdf (accessed 4 April 2019).

18. National Committee for Confidential Enquiry into Maternal Deaths. Saving Mothers 2017 Annual Report on Confidential Inquiries into Maternal Death in South Africa. Pretoria: National Department of Health, 2018

19. Pattinson R, Tlebere P. Introduction, methods and definition of the survey. In: Pattinson R, ed Saving Babies: A Perinatal Care Survey of South Africa. Pretoria: MRC Unit for Maternal and Infant Health Care Strategies, 2000:1-7. https://www.ppip.co.za/wp-content/uploads/Saving-babies-2000. pdf (accessed 2 December 2018).

20. World Health Organization. WHO Recommendations: Intrapartum Care for a Positive Child birth Experience. Geneva: WHO, 2018. http://apps.who.int/iris/bitstream/handle/10665 260178/9789241550215-eng.pdf;jsessionid=612D5E6FDB7BC731A926A521C3CD53AB?sequen ce $=1$ (accessed 2 December 2018).

Accepted 23 July 2019. 